\title{
Meta-analyses of 4 CFTR variants associated with the risk of the congenital bilateral absence of the vas deferens
}

Xuting Xu ${ }^{1+}$, Jufen Zheng ${ }^{3 \dagger}$, Qi Liao ${ }^{1}$, Huiqing Zhu ${ }^{1}$, Hongyan Xie ${ }^{1}$, Huijuan Shi ${ }^{2^{*}}$ and Shiwei Duan ${ }^{1 *}$

\begin{abstract}
Aims: The aim of our study was to evaluate the relationship between four CFTR variations and the congenital bilateral absence of the vas deferens (CBAVD).

Methods: A systematic search was performed in the literature databases for the case-control studies of CFTR variations with the risk of CBAVD. A total of 29 studies among 1139 controls and 1562 CBAVD patients were gathered for the meta-analyses of three commonly tecsted variations (5T, $\triangle F 508$ and M470V) with CBAVD.

Results: Our meta-analyses observed significant associations between CBAVD and all the three variations, including 5T $(\mathrm{P}<0.001, \mathrm{OR}=8.35,95 \% \mathrm{Cl}=6.68-10.43), \mathrm{M} 470 \mathrm{~V}(\mathrm{P}=0.027, \mathrm{OR}=0.74,95 \% \mathrm{Cl}=0.60-0.91)$ and $\Delta \mathrm{F} 508(\mathrm{P}<0.001$, $\mathrm{OR}=22.20,95 \% \mathrm{Cl}=7.49-65.79$ ).

Conclusion: In the current study, we demonstrated a significant association between CFTR variations and CBAVD. Our results showed that the 5T variation was a risk factor of CBAVD in French, Spanish, Japanese, Chinese, Iranian, Indian, Mexican and Egyptian populations. CFTR $\triangle$ F508 was another important risk factor in Caucasians, including Slovenians, Canadians, Iranians, and Egyptians. In addition, M470V was a protective factor among French, Chinese, Italian and Iranian populations.
\end{abstract}

Keywords: Congenital bilateral absence of the vas deferens, Meta-analysis, CFTR gene, 5T, $\triangle F 508$, M470V

\section{Introduction}

Congenital bilateral absence of the vas deferens (CBAVD, MIM: \#277180) is one of the abnormal forms in the male reproductive system, causing obstruction to sperm outflow into the urethra. CBAVD is responsible for $1-2 \%$ of male infertility [1]. CBAVD was widely considered as an atypical symptom of cystic fibrosis (CF, MIM: \#219700) $[2,3]$, which was a severe recessive disease characterized by obstructive chronic lung disease, pancreatic disease and abnormal concentrations of electrolytes in the sweat in clinical studies [4]. Approximately $97 \%$ of the male CF patients also suffered from CBAVD [5].

\footnotetext{
*Correspondence: shihuijuan@sippr.stc.sh.cn; duanshiwei@nbu.edu.cn ${ }^{\dagger}$ Equal contributors

${ }^{2}$ China National Population and Family Planning Key Laboratory of Contraceptive Drugs and Devices, Shanghai Institute of Planned Parenthood Research (SIPPR), Shanghai 200032, China

'Zhejiang Provincial Key Laboratory of Pathophysiology, School of Medicine, Ningbo University, Ningbo, Zhejiang 315211, China

Full list of author information is available at the end of the article
}

$\mathrm{CF}$ is a severe genetic disease with a incidence of $1 / 2500$ births every year in Caucasians [6]. CF patients are often carriers of CFTR gene variations [7] that were originally found in CBAVD patients $[8,9]$. The CFTR gene encodes a glycosylated transmembrane protein that is a chloride channel conducts the regulation of other transport pathways. CFTR was widely expressed in epithelial cells of exocrine tissues, such as the sweat glands, lungs, and vas deferens [10]. Published studies have shown evidence that abnormal expression of CFTR contributed to the dysfunction of body organs, including the sweat glands, respiratory system and reproductive systems. CBAVD is one of the generally acknowledged monosymptomatic CFTRrelated disorders [11].

Located on chromosome 7q31.2, the CFTR gene contains 27 exons and 1945 polymorphisms according to the Cystic Fibrosis Variations Database [12]. There are four commonly tested variations $(\Delta \mathrm{F} 508,5 \mathrm{~T}, \mathrm{M} 470 \mathrm{~V}$ and $\mathrm{R} 1117 \mathrm{H}$ ) in CBAVD. 
The abnormal fold of the $\triangle$ F508-CFTR protein triggered the activity of proteasomes for degradation, which caused a lower open probability than normal [13]. Another common variations, IVS8-Tn, had three forms containing five, 7 seven, or 9 nine thymidine residues in this locus, which is considered an incomplete penetrance [14]. The 5T allele especially produces high levels of CFTR transcript without exon 9, resulting in variable phenotypes which were observed in CBAVD or mild CF patients [4]. Experimental evidence indicates that $5 \mathrm{~T}$ carriers have a decreased splicing efficiency of intron 8 $[15,16]$. M470V $(1540 \mathrm{~A} / \mathrm{G}$ in exon 10) is in a strong linkage disequilibrium with the $5 \mathrm{~T}$ locus in the CBAVD population, and has become a commonly tested locus [17-19]. The 470V-CFTR protein has lower function than the 470M-CFTR protein [20]. There were arguments on the role of $\mathrm{M} 470 \mathrm{~V}$ in the CBAVD, although M470V might increase the penetrance of $5 \mathrm{~T}$ and lead to an obvious association between $5 \mathrm{~T}$ and Val470 alleles in CBAVD but not in fertile males.

CBAVD incidence is rare $(1-2 \%)$ in the patients with male infertility [1]. Most genetic studies only involved a few number of individuals. Meanwhile, there was large ethnic difference for the CFTR variations that were more frequent in Caucasians than in other populations, such as Asians. Meta-analysis has an advantage in the sample size by pooling all the relational studies. In the present study, we performed a comphrehensive search for the eligible case-control studies on the association between CBAVD and three CFTR variations, including F508del, IVS8-Tn, and M470V. The goal of our study was to evaluate the overall contribution of the three CFTR variations to the risk of CBAVD in different ethnic groups through systematic meta-analyses.

\section{Materials and methods}

Literature search and study selection

The search terms including CBAVD, SNP or variations and CFTR gene were used in the literature search on the PubMed. We investigated all publications on the association between CFTR variants and CBAVD disease from 1993 to 2013. Reference lists in the harvested literatures were explored for additional relevant studies suitable for inclusion in our meta-analysis. The selection criteria of studies for our meta-analysis were as follows: (1) CBAVD patients with typical CF were excluded; (2) complete data with allele or genotype in the case-control studies was available; (3) only CBAVD diagnosis for studies with physical examination, semen analysis and ultrasonography were considered. The retrieved information consisted of author, year of publication, ethnicity, and the number of participants with different alleles.

\section{Statistical analysis}

All the eligible case-control studies were involved in the meta-analysis done by Stata software (version 11.0, Stata Corporation, College Station, TX) [21]. Total odd ratios (OR) and 95\% confidence intervals (CIs) were estimated to assess the association between CFTR variations and CBAVD risk. Cochran's Q statistic and $\mathrm{I}^{2}$ test were used to test heterogeneity in our study. The Fixed-effect model was used for meta-analysis with moderate heterogeneity $\left(\mathrm{I}^{2}<50 \%\right)$. Otherwise, a random-effect model was adopted for the meta-analysis with significant heterogeneity $\left(\mathrm{I}^{2}>=50 \%\right) \quad[22,23]$. Z-test with a twosided $P$ value $<0.05$ was used to determine the significance of the total ORs. The publication bias in the meta-analysis was evaluated by the funnel plot and Egger's test. Summary analysis of the overall frequency of all the studies was executed to show the frequency for all fou variations [24]. Subgroup analysis was performed by ethnicity to evaluate the effect of different ethnicity on total ORs.

\section{Results}

Our comprehensive literature search returned a total of 149 articles on the association between CFTR and CBAVD from PubMed and two studies from CNKI. A total of 104 studies was harvested after being filtered by their titles and abstracts. Among those articles, we removed four family studies and three reviews or metaanalysis. Consequently, 26 studies without obtainable allele or genotype data were removed. Among them, there were 29 studies on three CFTR variations. Our meta-analyses of three CFTR variations were performed among 1139 cases and 1563 controls (Figure 1, Table 1).

A strong association between the CFTR $5 \mathrm{~T}$ variant and CBAVD was observed in the meta-analysis of 19 studies

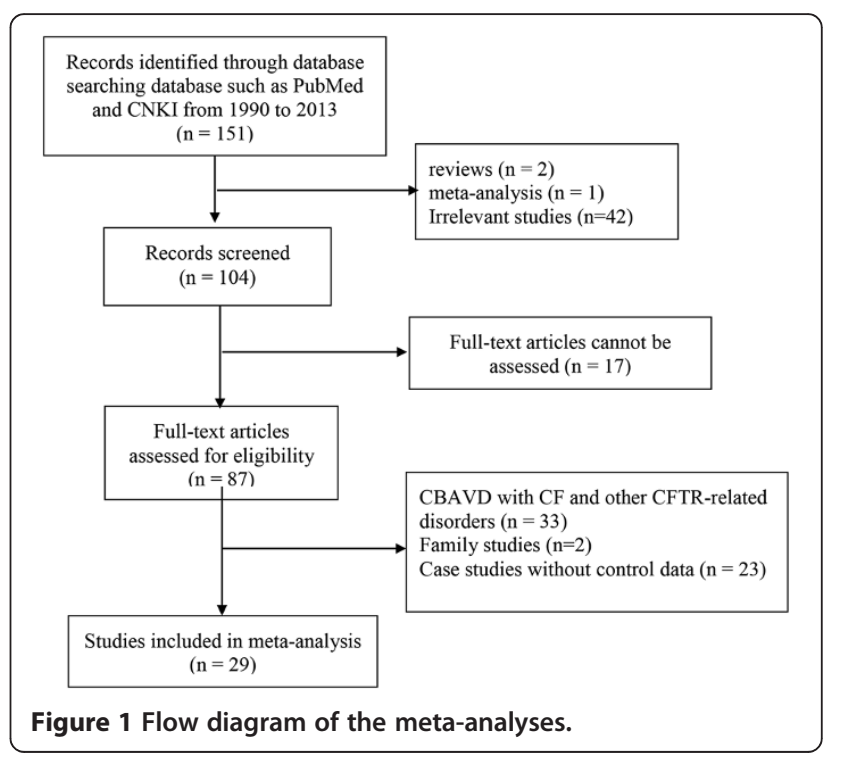


Table 1 The characteristics of the enrolled mutation for OR meta-analysis

\begin{tabular}{|c|c|c|c|c|c|c|c|c|c|}
\hline Mutation & Author & Ethnic & Year & Total (case/control) & Allele (case/control) & Total1 & Allele1 & Total2 & Allele2 \\
\hline \multirow[t]{19}{*}{ T5 } & Costes & French & 1995 & $45 / 66$ & $23 / 7$ & 90 & 23 & 131 & 7 \\
\hline & Chillon & Spanish & 1995 & $102 / 46$ & $42 / 5$ & 204 & 42 & 92 & 5 \\
\hline & de Meeus & French & 1998 & $60 / 133$ & 20/11 & 120 & 20 & 266 & 11 \\
\hline & Casals & Spanish & 2000 & $104 / 200$ & $41 / 20$ & 208 & 41 & 400 & 20 \\
\hline & Ravnik-Glavac & Slovenia & 2001 & $7 / 95$ & $3 / 8$ & 14 & 3 & 190 & 8 \\
\hline & Anzai & Japanese & 2003 & $19 / 53$ & $11 / 0$ & 38 & 11 & 106 & 0 \\
\hline & Grangeia & Caucasian & 2004 & $31 / 114$ & $17 / 8$ & 62 & 17 & 228 & 8 \\
\hline & Wu, C. C. & Chinese & 2004 & $27 / 46$ & $34 / 5$ & 54 & 34 & 92 & 5 \\
\hline & Wu, C. C. & Chinese & 2005 & $36 / 23$ & $21 / 1$ & 72 & 21 & 46 & 1 \\
\hline & Radpour, R. & Iranian & 2006 & $106 / 43$ & $55 / 0$ & 212 & 55 & 86 & 0 \\
\hline & Wilschanski & Canadian & 2006 & $60 / 31$ & $22 / 2$ & 120 & 22 & 62 & 2 \\
\hline & Radpour, R. & Iranian & 2007 & $112 / 84$ & $61 / 0$ & 224 & 61 & 168 & 0 \\
\hline & Costa & NA & 2008 & $68 / 62$ & $33 / 6$ & 136 & 33 & 124 & 6 \\
\hline & Chiang & Chinese & 2009 & $63 / 86$ & $42 / 6$ & 126 & 42 & 172 & 6 \\
\hline & Sharma & Indian & 2009 & $39 / 50$ & $21 / 5$ & 78 & 21 & 100 & 5 \\
\hline & Sachdeva & Indian & 2011 & $35 / 50$ & $19 / 1$ & 70 & 19 & 100 & 1 \\
\hline & Hussein & Egyptian & 2011 & $30 / 30$ & $16 / 3$ & 60 & 16 & 60 & 3 \\
\hline & Saldana-Alvarez & Mexican & 2012 & $16 / 103$ & $1 / 3$ & 32 & 1 & 206 & 3 \\
\hline & LU & Chinese & 2013 & 109/104 & $97 / 28$ & 218 & 97 & 208 & 28 \\
\hline \multirow[t]{5}{*}{$\Delta \mathrm{F} 508$} & Ravnik-Glavac & Slovenia & 2001 & $7 / 95$ & $2 / 3$ & 14 & 2 & 190 & 3 \\
\hline & Kusic, J. & NA & 2002 & 10/11 & $5 / 1$ & 20 & 5 & 22 & 1 \\
\hline & Wilschanski, M. & Canadian & 2006 & $60 / 31$ & $30 / 1$ & 120 & 30 & 62 & 1 \\
\hline & Radpour, R. & Iranian & 2007 & $112 / 84$ & $28 / 0$ & 224 & 28 & 168 & 0 \\
\hline & Hussein, T. M. & Egyptian & 2011 & $30 / 30$ & $12 / 0$ & 60 & 12 & 60 & 0 \\
\hline \multirow[t]{5}{*}{ M470V } & de Meeus, A. & French & 1998 & $60 / 133$ & $52 / 158$ & 120 & 52 & 266 & 158 \\
\hline & Wu, C. C. & Chinese & 2005 & $36 / 53$ & $35 / 61$ & 72 & 35 & 106 & 61 \\
\hline & Stuppia, L. & Italian & 2005 & $13 / 54$ & $4 / 38$ & 26 & 4 & 108 & 38 \\
\hline & Radpour, R. & Iranian & 2006 & $106 / 43$ & $69 / 21$ & 212 & 69 & 86 & 21 \\
\hline & Du, Qing & Chinese & 2013 & $95 / 135$ & $99 / 158$ & 190 & 99 & 270 & 158 \\
\hline
\end{tabular}

among 1069 cases and 1419 controls $(\mathrm{OR}=8.35,95 \%$ $\mathrm{CI}=6.03-10.81$, Figure 2). Our results also found that $\triangle \mathrm{F} 508$ was a risk factor of CBAVD $(\mathrm{OR}=22.2,95 \% \mathrm{CI}=$ 7.49-65.79, Figure 2). Our meta-analysis showed the M470V variation was associated with CBAVD $(\mathrm{OR}=0.74$, $95 \% \mathrm{CI}=0.60-0.91$, Figure 2). Future study is required to explore whether there are other causal variants in high linkage disequilibrium with M470V.

As shown in Figure 2, moderate heterogeneity was observed for CFTR $5 \mathrm{~T}\left(\mathrm{I}^{2}=44.0 \%\right)$, M470V $\left(\mathrm{I}^{2}=61.0 \%\right)$ and $\Delta \mathrm{F} 508\left(\mathrm{I}^{2}=0.00 \%\right)$. Furthermore, subgroup metaanalyses of the $5 \mathrm{~T}$ variations by ethnicity showed that the heterogeneity mainly came from Asians $\left(\mathrm{I}^{2}=71.5 \%\right)$ instead of Caucasians $\left(\mathrm{I}^{2}=30.0 \%\right)$. Our results indicated that $5 \mathrm{~T}$ was a risk factor of CBAVD in Caucasians (OR = 8.07, 95\% CI $=6.03-10.81, P=0.00$, Figure 2), as well as in Asians $(\mathrm{OR}=9.31,95 \% \mathrm{CI}=6.42-13.49, \mathrm{P}=0.00$, Figure 2$)$.
As shown in the funnel plot, no obvious publication bias was observed for the meta-analyses (Figure 3 ). The results of meta-analyses were robust after the removal of individual studies (Figure 4).

\section{Discussion}

In the present study, we carried out a systematic overview of the studies for a genetic link with CBAVD. Significant evidence was observed (that showed) the strong association with CBAVD onset with the risk of CBAVD for all the three variations, including $5 \mathrm{~T}(\mathrm{OR}=8.35,95 \% \mathrm{CI}=6.03-10.81$, Figure 2), $\mathrm{M} 470 \mathrm{~V}(\mathrm{OR}=0.74,95 \% \mathrm{CI}=0.60-0.91$, Figure 2$)$ and $\Delta \mathrm{F} 508(\mathrm{OR}=22.2,95 \% \mathrm{CI}=7.49-65.79$, Figure 2$)$.

Among the tested variations, M470V was the only one with the protective role of CBAVD. V470 carriers tended to have a higher fertility than other carriers, suggesting that there might be competing and evolutionary forces 


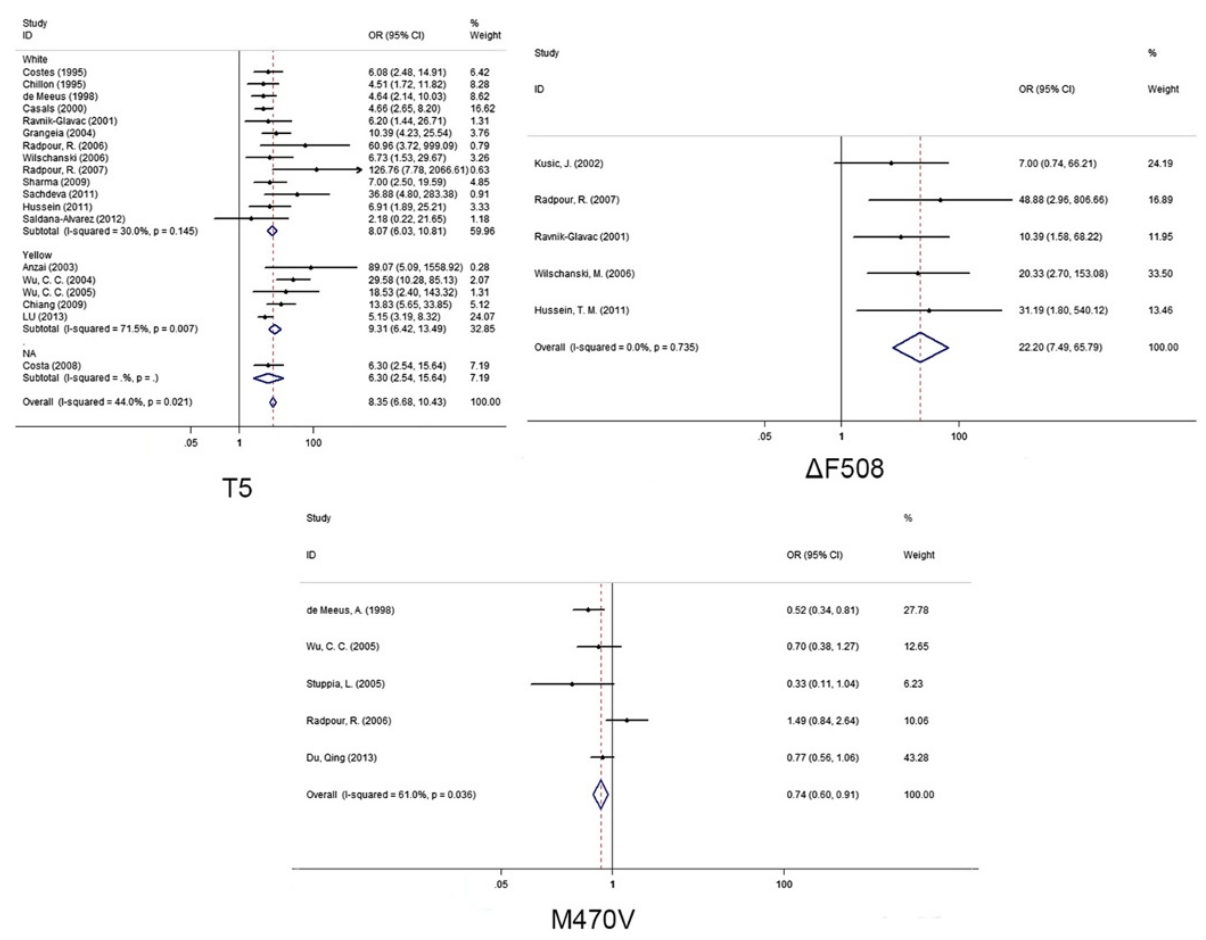

Figure 2 Forest plots for the relationship between 3 variations and CBAVD in the meta-analyses and subgroup meta-analyses.
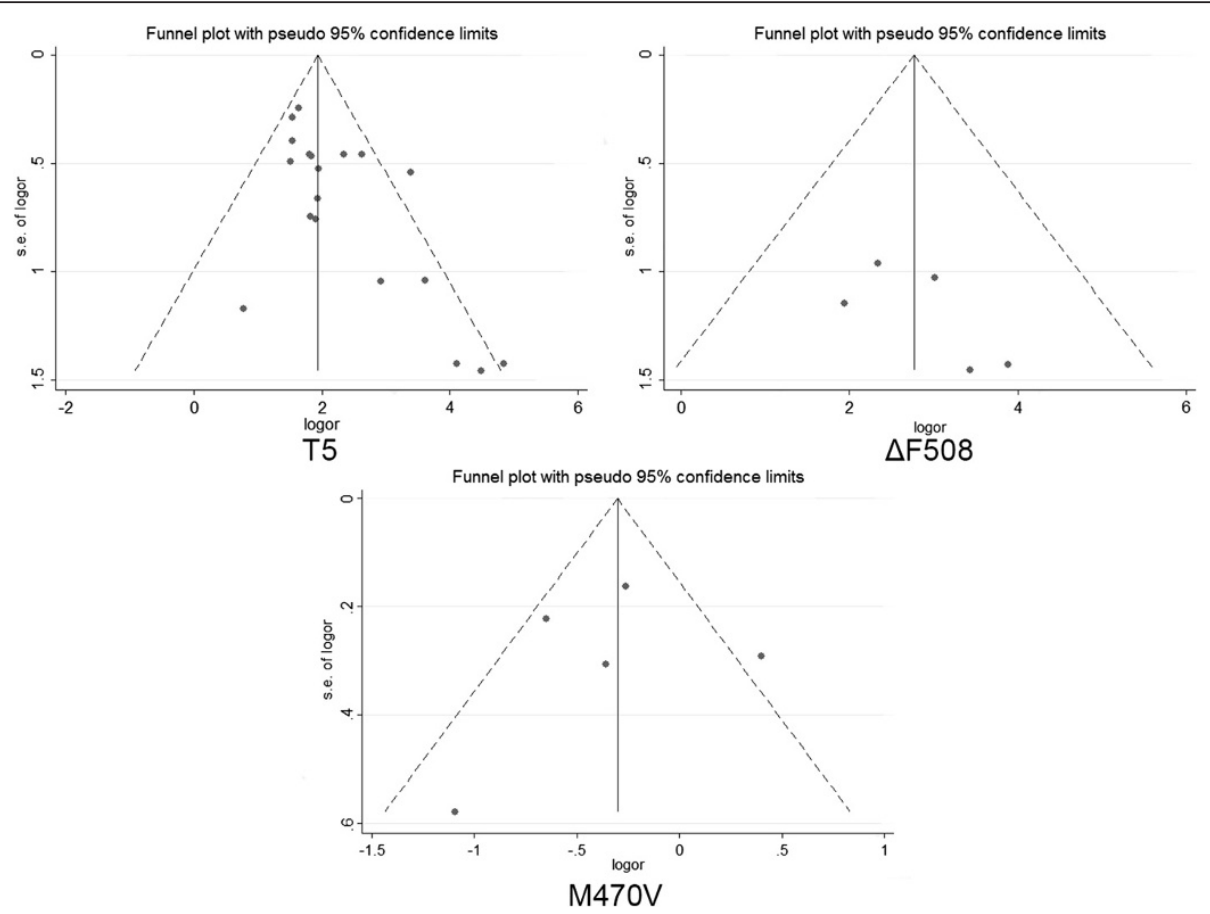

Figure 3 Funnel plots for the relationship between 3 variations and CBAVD in the meta-analyses. 


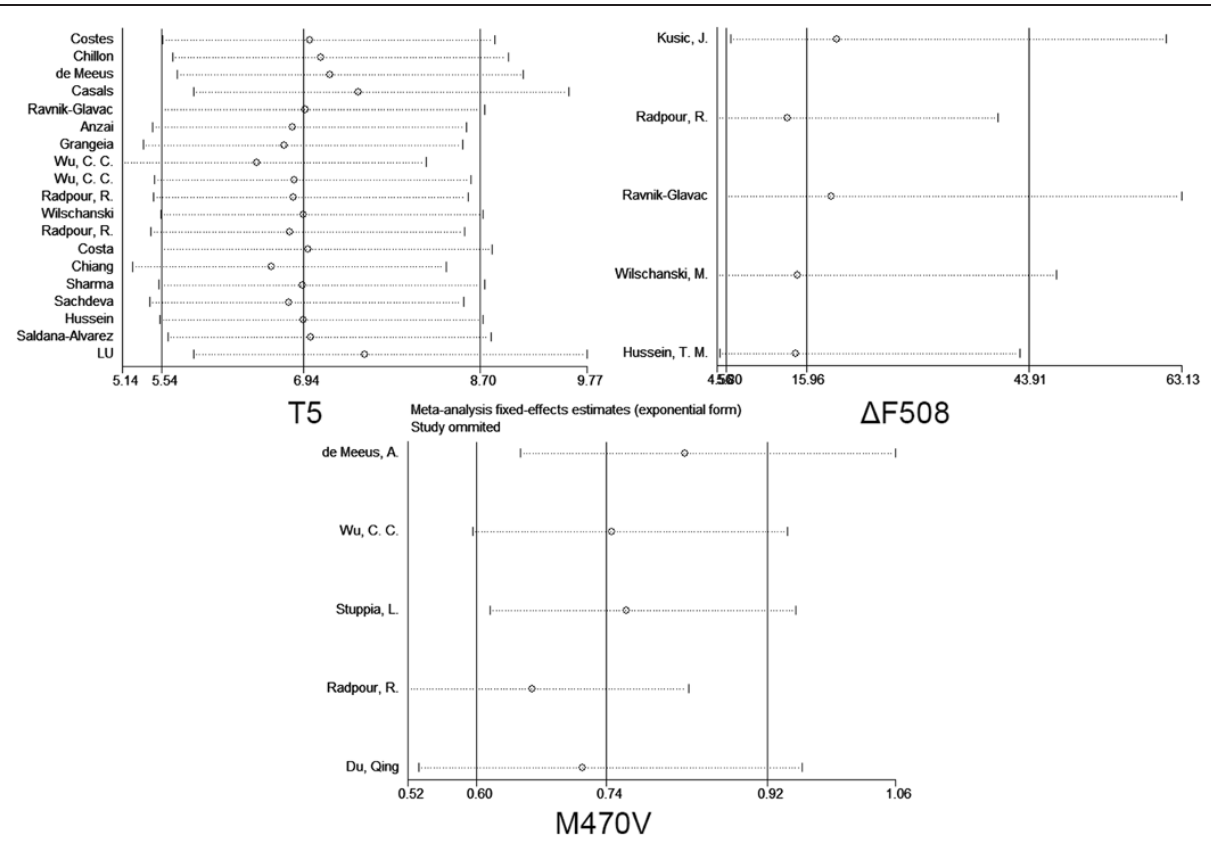

Figure 4 Meta influence analysis for 3 variations.

acting on the CFTR gene [25]. Furthermore, the interaction of the variations might affect the risk of CBAVD [26,27]. In addition, the haplotypes of these variations can significantly contribute to the susceptibility of CBAVD alone or together with the SPINK1 locus [11]. Further detailed studies are required to provide evidence that independent CBAVD rather than CBAVD with CF is associated with CFTR variations.

Several limitations in our meta-analyses were taken into consideration as followed. Firstly, some studies did not reveal whether CBAVD patients were isolated CBAVD patients or patients with CF symptoms for the incomplete information. This might potentially interfere with the results of our meta-analyses. Secondly, the power of our meta-analyses is still low due to low allele frequency of these variations. Under a moderate risk of $\mathrm{OR}(\mathrm{OR}=1.2)$, power analysis showed a lack of power in the metaanalyses, including 5T (47.3\%), $\Delta$ F508 (7.1\%) of LPL, and M470V (52.1\%). Thirdly, there was a lack of haplotype information among these loci in most of involved studies. Reports have shown there were interactions among these variations [28-30]. We discontinued the further analysis for examining variables, including interaction between the two or three loci.

In conclusion, the present study demonstrated an association between CFTR variants and CBAVD risk. Our meta-analysis among 1069 cases and 1418 controls showed that $5 \mathrm{~T}$ was a risk factor of CBAVD in the combined populations, including French, Spanish, Japanese, Chinese, Iranian, Indian, Mexican and Egyptian. Metaanalysis among 60 cases and 133 controls confirmed that CFTR $\triangle \mathrm{F} 508$ was another important risk factor in
Caucasian populations including Slovenian, Canadian, Iranian and Egyptian. In addition, M470V was shown to be a protective factor by our meta-analysis among 10 cases and 11 controls from French, Chinese, Italian and Iranian populations.

\section{Abbreviations}

SNP: Single nucleotide polymorphism; CBAVD: Congenital bilateral absence of the vas deferens; CF: Cystic fibrosis; OR: Odds ratio; 95\% Cl: 95\% confidence interval; $I^{2}$ : Inconsistency index.

\section{Competing interests}

All authors declare no competing financial interests.

\section{Authors' contributions}

XTX drafted the manuscript; JZ and QL were responsible for analysis; HZ and HX participated in literature search. SJ and SD carried out language editing. All authors read and approved the final manuscript.

\section{Acknowledgments}

The research was supported by the grants from the Shanghai Committee of Science and Technology, China (Grant No. 09411964200), the Major State Basic Research Development Program of China (973 Program, No. 09411964200), National Natural Science Foundation of China (31100919, 81371469 and 81270744), Key Program of Shanghai Municipal Science and technology (10JC1409900, 10JC1410800 and 11411950100), Natural Science Foundation of Zhejiang Province (LR13H020003), Ningbo social development research projects (2012C50032) and K.C. Wong Magna Fund in Ningbo University.

\section{Author details}

'Zhejiang Provincial Key Laboratory of Pathophysiology, School of Medicine, Ningbo University, Ningbo, Zhejiang 315211, China. ${ }^{2}$ China National

Population and Family Planning Key Laboratory of Contraceptive Drugs and Devices, Shanghai Institute of Planned Parenthood Research (SIPPR), Shanghai 200032, China. ${ }^{3}$ China National Population and Family Planning Key Laboratory of Contraceptive Drugs and Devices, SIPPR, Fudan University, Shanghai 200032, China. 
Received: 15 April 2014 Accepted: 24 July 2014

Published: 21 August 2014

\section{References}

1. Grangeia A, Barro-Soria R, Carvalho F, Damas AM, Mauricio AC, Kunzelmann K, Barros A, Sousa M: Molecular and functional characterization of CBAVDcausing mutations located in CFTR nucleotide-binding domains. Cell Physiol Biochem 2008, 22:79-92.

2. Holsclaw DS, Perlmutter AD, Jockin H, Shwachman H: Genital abnormalities in male patients with cystic fibrosis. J Urol 1971, 106:568-574.

3. Kaplan E, Shwachman H, Perlmutter AD, Rule A, Khaw KT, Holsclaw DS: Reproductive failure in males with cystic fibrosis. N Engl J Med 1968, 279:65-69.

4. Ghorbel M, Baklouti-Gargouri S, Keskes R, Sellami-Ben Hamida A, Feki-Chakroun N, Bahloul A, Fakhfakh F, Ammar-Keskes L: Screening of DeltaF508 mutation and IVS8-poly T polymorphism in CFTR gene in Tunisian infertile men without CBAVD. Andrologia 2012, 44(Suppl 1):376-382.

5. Wang Z, Milunsky J, Yamin M, Maher T, Oates R, Milunsky A: Analysis by mass spectrometry of 100 cystic fibrosis gene mutations in 92 patients with congenital bilateral absence of the vas deferens. Hum Reprod 2002, 17:2066-2072.

6. Kerem B, Chiba-Falek O, Kerem E: Cystic fibrosis in Jews: frequency and mutation distribution. Genet Test 1997, 1:35-39.

7. Riordan JR, Rommens JM, Kerem B, Alon N, Rozmahel R, Grzelczak Z Zielenski J, Lok S, Plavsic N, Chou JL, et al: Identification of the cystic fibrosis gene: cloning and characterization of complementary DNA Science 1989, 245:1066-1073.

8. Dumur V, Gervais R, Rigot JM, Lafitte JJ, Manouvrier S, Biserte J, Mazeman E, Roussel P: Abnormal distribution of CF delta F508 allele in azoospermic men with congenital aplasia of epididymis and vas deferens. Lancet 1990, 336:512.

9. Oates RD, Amos JA: The genetic basis of congenital bilateral absence of the vas deferens and cystic fibrosis. J Androl 1994, 15:1-8.

10. O'Sullivan BP, Freedman SD: Cystic fibrosis. Lancet 2009, 373:1891-1904.

11. Steiner B, Rosendahl J, Witt H, Teich N, Keim V, Schulz HU, Pfutzer R, Lohr M, Gress TM, Nickel R, Landt O, Koudova M, Macek M Jr, Farre A, Casals T, Desax MC, Gallati S, Gomez-Lira M, Audrezet MP, Ferec C, Des Georges M, Claustres $M$, Truninger $\mathrm{K}$ : Common CFTR haplotypes and susceptibility to chronic pancreatitis and congenital bilateral absence of the vas deferens. Hum Mutat 2011, 32:912-920.

12. Cystic Fibrosis Mutation Database. [http://www.genet.sickkids.on.ca/cftr/app]

13. Lukacs GL, Verkman AS: CFTR: folding, misfolding and correcting the DeltaF508 conformational defect. Trends Mol Med 2012, 18:81-91.

14. Chillon M, Casals T, Mercier B, Bassas L, Lissens W, Silber S, Romey MC, Ruiz-Romero J, Verlingue C, Claustres M, et al: Mutations in the cystic fibrosis gene in patients with congenital absence of the vas deferens. N Engl J Med 1995, 332:1475-1480.

15. Chu CS, Trapnell BC, Curristin S, Cutting GR, Crystal RG: Genetic basis of variable exon 9 skipping in cystic fibrosis transmembrane conductance regulator mRNA. Nat Genet 1993, 3:151-156.

16. Teng $H$, Jorissen M, Van Poppel H, Legius E, Cassiman JJ, Cuppens H: Increased proportion of exon 9 alternatively spliced CFTR transcripts in vas deferens compared with nasal epithelial cells. Hum Mol Genet 1997, 6:85-90.

17. de Meeus A, Guittard C, Desgeorges M, Carles S, Demaille J, Claustres M: Linkage disequilibrium between the M470V variant and the IVS8 polyT alleles of the CFTR gene in CBAVD. J Med Genet 1998, 35:594-596.

18. Wu CC, Alper OM, Lu JF, Wang SP, Guo L, Chiang HS, Wong LJ: Variations spectrum of the CFTR gene in Taiwanese patients with congenital bilateral absence of the vas deferens. Hum Reprod 2005, 20:2470-2475.

19. Groman JD, Hefferon TW, Casals T, Bassas L, Estivill X, Des Georges M, Guittard C, Koudova M, Fallin MD, Nemeth K, Fekete G, Kadasi L, Friedman K, Schwarz M, Bombieri C, Pignatti PF, Kanavakis E, Tzetis M, Schwartz M, Novelli G, D'Apice MR, Sobczynska-Tomaszewska A, Bal J, Stuhrmann M, Macek M Jr, Claustres M, Cutting GR: Variation in a repeat sequence determines whether a common variant of the cystic fibrosis transmembrane conductance regulator gene is pathogenic or benign. Am J Hum Genet 2004, 74:176-179.

20. Ni WH, Jiang L, Fei QJ, Jin JY, Yang X, Huang XF: The CFTR polymorphisms poly-T, TG-repeats and M470V in Chinese males with congenital bilateral absence of the vas deferens. Asian J Androl 2012, 14:687-690.
21. Lian J, Huang Y, Huang RS, Xu L, Le Y, Yang X, Xu W, Huang X, Ye M, Zhou J, Duan S: Meta-analyses of four eosinophil related gene variants in coronary heart disease. J Thromb Thrombolysis 2013, 36:394-401.

22. Higgins JP, Thompson SG, Deeks JJ, Altman DG: Measuring inconsistency in meta-analyses. BMJ 2003, 327:557-560.

23. DerSimonian R, Laird N: Meta-analysis in clinical trials. Control Clin Trials 1986, 7:177-188

24. Yu J, Chen Z, Ni Y, Li Z: CFTR mutations in men with congenital bilateral absence of the vas deferens (CBAVD): a systemic review and meta-analysis. Hum Reprod 2012, 27:25-35.

25. Kosova G, Pickrell JK, Kelley JL, McArdle PF, Shuldiner AR, Abney M, Ober C The CFTR Met 470 allele is associated with lower birth rates in fertile men from a population isolate. PLoS Genet 2010, 6:e1000974.

26. Tamburino L, Guglielmino A, Venti E, Chamayou S: Molecular analysis of mutations and polymorphisms in the CFTR gene in male infertility. Reprod Biomed Online 2008, 17:27-35.

27. Stuppia L, Antonucci I, Binni F, Brandi A, Grifone N, Colosimo A, De Santo M, Gatta V, Gelli G, Guida V, Majore S, Calabrese G, Palka C, Ravani A, Rinaldi R, Tiboni GM, Ballone E, Venturoli A, Ferlini A, Torrente I, Grammatico P, Calzolari E, Dallapiccola B: Screening of mutations in the CFTR gene in 1195 couples entering assisted reproduction technique programs. Eur J Hum Genet 2005, 13:959-964.

28. Boudaya M, Fredj SH, Haj RB, Khrouf M, Bouker A, Halouani L, Messaoud T: Cystic fibrosis transmembrane conductance regulator mutations and polymorphisms associated with congenital bilateral absence of vas deferens in a restricted group of patients from North Africa. Ann Hum Biol 2012, 39:76-79.

29. Sun W, Anderson B, Redman J, Milunsky A, Buller A, McGinniss MJ, Quan F, Anguiano A, Huang S, Hantash F, Strom C: CFTR 5T variant has a low penetrance in females that is partially attributable to its haplotype. Genet Med 2006, 8:339-345.

30. Borden W, Berlin S: Gender, coping, and psychological well-being in spouses of older adults with chronic dementia. Am J Orthopsychiatry 1990, 60:603-610.

doi:10.1186/2043-9113-4-11

Cite this article as: Xu et al:: Meta-analyses of 4 CFTR variants associated with the risk of the congenital bilateral absence of the vas deferens. Journal of Clinical Bioinformatics 2014 4:11.

\section{Submit your next manuscript to BioMed Central and take full advantage of:}

- Convenient online submission

- Thorough peer review

- No space constraints or color figure charges

- Immediate publication on acceptance

- Inclusion in PubMed, CAS, Scopus and Google Scholar

- Research which is freely available for redistribution

Submit your manuscript at www.biomedcentral.com/submit
C) Biomed Central 